\title{
Projetos de Pesquisa
}





\section{(De)marcando a cidade: vivências urbanas de jovens-estudantes do Colégio de Aplicação da UFRGS}

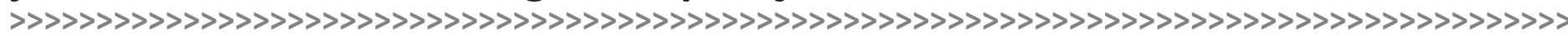

Victor Hugo Nedel Oliveira*

\section{Resumo:}

Entender as juventudes contemporâneas e suas relações com a cidade faz-se oportuno em uma sociedade que, cada vez mais, subestima as capacidades destes sujeitos. Este estudo objetiva analisar as percepções e experiências urbanas vivenciadas por jovens escolarizados do Colégio de Aplicação da UFRGS. Como aporte teórico, recorre-se aos autores que são referências no campo das juventudes e no campo das questões urbanas. Para tanto, realiza-se a metodologia quantitativo-qualitativa, através do uso de quatro movimentos metodológicos, o primeiro sendo um questionário autoaplicável pelos sujeitos da pesquisa. O segundo movimento metodológico é a escrita de uma carta ao turista. O terceiro movimento metodológico são observações em campo, a partir de formulário próprio. O quarto movimento, no sentido de amarrar os três anteriores e verificar pontos pendentes, constitui-se da realização de grupo focal, com metodologia de trabalho própria.

\section{Palavras-chave:}

Juventudes. Cidade. Educação.

\section{Resumen:}

Entender las juventudes contemporáneas y sus relaciones con la ciudad se hace oportuno en una sociedad que, cada vez más, subestima las capacidades de estos sujetos. Este estudio objetiva analizar las percepciones y experiencias urbanas vivenciadas por jóvenes escolarizados del Colegio de Aplicación de la UFRGS. Como aporte teórico, se recurre a los autores referencias en el campo de las juventudes y en el campo de las cuestiones urbanas. Para eso, se realiza la metodología cuantitativo-cualitativa, a través del uso de cuatro movimientos metodológicos, el primero siendo un cuestionario autoaplicable por los sujetos de la investigación. El segundo movimiento metodológico es la escritura de una carta al turista. El tercer movimiento metodológico son observaciones en campo, a partir de formulario propio. El cuarto movimiento, en el sentido de atar los tres anteriores y verificar puntos pendientes, se constituye de la realización de un grupo focal, con metodología de trabajo propia.

\section{Palabras-clave:}

Juventudes. Ciudad. Educación.

\section{Introdução e Justificativa}

O tema culturas juvenis é alvo de importantes discussões na sociedade contemporânea, uma vez que a juventude vem configurando-se como importante etapa da vida

* > Mestre em Geografia (UFRGS). Professor de Geografia do Departamento de Humanidades do Colégio de Aplicação da UFRGS. E-mail: victornedelcap@ gmail.com. 
humana, formada por constantes transformações e muitas vezes reconhecida como o ideal da cultura, transformações estas as quais possibilitam diversas análises (PAIS, 2001).

Em uma contextualização inicial, podemos apresentar os números das juventudes nas escalas geográficas envolvidas: no Brasil, são aproximadamente 51 milhões de habitantes que possuem entre 15 e 29 anos, classificação apontada pelo Instituto Brasileiro de Geografia e Estatística (IBGE, 2010); no Rio Grande do Sul, são mais de 2,5 milhões de jovens (FEE, 2016); e em Porto Alegre mais de 330 mil sujeitos são enquadrados nesta faixa etária (FEE, 2016).

No âmbito da educação, constatamos a realidade de escolas que, em muitos casos, não dialogam com seus interlocutores: sujeitos-alunos-jovens. É crescente o número de pesquisas (WARTHA; SILVA; BEJARANO, 2013; KATO; KAWASAKI, 2011; CALADO, 2012) que apontam para a necessidade de contextualizar o ensino, haja vista que o mesmo se encontra em situação de distanciamento em relação às vivências dos jovens.

A cidade, por sua vez, constitui-se no espaço de vida social da maioria absoluta dos brasileiros, muitos deles jovens. É no espaço urbano que as relações sociais das juventudes se estabelecem em sua plenitude. E é na geografia escolar que se encontra o ápice das discussões sobre a cidade: sejam nas aulas de Geografia Urbana, especificamente, ou nas discussões estabelecidas transversalmente sobre o tema das cidades e das questões urbanas (CAVALCANTI, 2008).

Diante deste contexto, aumenta a responsabilidade de pensar em estratégias que possibilitem: (a) um conhecimento maior sobre quem é o aluno contemporâneo, independente de sua realidade de origem, para que possa haver a interlocução professor-aluno; e (b) quais são as relações destes sujeitos com o espaço urbano, na medida em que os espaços são vividos e percebidos pelos mesmos, constituindo-se assim, a rede de fluxos urbanos.

Formula-se a presente pergunta de pesquisa, no sentido de que possa orientar os trabalhos e as etapas metodológicas: "Como jovens do Colégio de Aplicação da UFRGS percebem e vivem a cidade de Porto Alegre e seus arredores?".

Cabe afirmar da escassez de estudos que envolvam diretamente os dois grandes eixos os quais esta pesquisa propõe-se a trabalhar: culturas juvenis e cidade. Existe uma necessidade eminente de entender melhor quem é o jovem contemporâneo, o qual se encontra nos bancos escolares: verificar suas origens, o que vislumbram para seu futuro e suas realidades de vida o que, por exemplo, possibilita aos professores melhor desempenhar suas atividades docentes, já que o planejamento pedagógico parte de uma realidade conhecida.

Nesta definição do que pesquisar procura-se realizar um estudo que contribua para a melhoria da educação geográfica e do entendimento de quem é o jovem-aluno, na medida em que o trabalho possa responder não apenas as perguntas que são feitas atualmente, mas também possa ter significado para outros professores, para além da própria Geografia. Não se afirma que todas as perguntas serão respondidas, mas se indica a intenção de contribuir com o avanço das discussões sobre o ensino de maneira geral e, especificamente, sobre o ensino de geografia, e para os jovens e seus entendimentos da cidade. Conhecer os jovens com os quais trabalhamos é importante, porque possibilita entendê-los para além do trabalho escolar.

\section{Objetivos}

\section{Objetivo geral}

Analisar as percepções e experiências urbanas vivenciadas pelos jovens escolarizados do Colégio de Aplicação da Universidade Federal do Rio Grande do Sul. 


\section{Objetivos específicos}

" Caracterizar os jovens participantes do estudo quanto aos aspectos socioeconômicos, culturais e afetivos;

" Cartografar, por meio de levantamento próprio, os espaços da cidade que pelos quais transitam os jovens participantes do estudo;

"Dialogar, com os jovens participantes deste estudo, sobre suas percepções e vivências urbanas;

"Construir, a partir dos levantamentos e resultados do projeto de pesquisa, um projeto de extensão no qual os jovens realizem intervenções urbanas, em locais destacados.

\section{Referencial teórico prévio}

para uma melhor compreensão dos eixos de análise a que o presente projeto de pesquisa se propõe a analisar, divide-se o referencial teórico nestes blocos: "As culturas juvenis" e "A cidade".

\section{As culturas juvenis}

Ao entrar em uma sala de aula, é impossível não notar a presença deles. Estão à frente de seus professores, falam com linguagem própria, gesticulam, utilizam vestimenta própria, escutam música, digitam no celular: são os jovens contemporâneos.

Essa temática das culturas juvenis é amplamente trabalhada por Feixa Pàmpols (1998, p. 32), quando afirma que:

\footnotetext{
En un sentido amplio, las culturas juveniles se refieren a la manera en que las experiencias sociales de los jóvenes son expresadas colectivamente mediante la construcción de estilos de vida distintivos, localizados fundamentalmente en el tiempo libre, o en espacios intersticiales de la vida institucional. ${ }^{1}$
}

Observa-se, nos estudos de Feixa Pàmpols (1998), que as culturas juvenis se formam na coletividade. É claro que existem muitos espaços não formais de aprendizagem e que os jovens se encontram em muitos outros espaços, como o espaço urbano. Além de investigar os espaços não formais de aprendizagem, este estudo propõe-se a verificar os comportamentos e falas dos sujeitos-jovens-alunos em diferentes espaços, e sua relação com a cidade.

Feixa Pàmpols (2004, p. 78) complementa sua definição de juventudes como sendo

[...] uma fase natural do desenvolvimento humano que se encontraria em todas as sociedades e momentos históricos, explicado pela necessidade de um período de preparação e amadurecimento entre a dependência infantil e a plena inserção social.

Essa fase de entremeio entre a infância e a inserção social, se definida em termos de escolarização, encontra seu encaixe no ensino médio, época escolar que varia, regularmente, dos 15 aos 17 anos de idade. Caberia questionar aqui o papel da formação do Ensino Médio nessa etapa de preparação e amadurecimento. Como os currículos vêm tratando essas questões? É possível que a formação do aluno abarque, para além dos programas curriculares, uma formação plena e cidadã? Como se utilizam as vivências da cidade pelos alunos contemporâneos nas aulas? Percebe-se, na história brasileira, que as juventudes normalmente foram grupo integrante, atuante, pensante e participante de muitos movimentos sociais e políticos.
$1>$ “Em um sentido amplo, as culturas juvenis se referem à maneira em que as experiências sociais dos jovens são expressas coletivamente mediante a construção de estilos de vida distintos, localizados fundamentalmente no tempo livre, ou em espaços intrínsecos da vida institucional." Tradução nossa. 
Entretanto, o aluno de hoje possui senso crítico de sua realidade. Mas ele executa, de fato, algo para mudá-la? Nesse caso, também entra em cena o papel da formação da escola, no sentido de discutir os temas atuais da sociedade brasileira com os alunos. Caccia-Bava e Costa (2004, p. 15, grifo nosso) já afirmaram esse histórico da juventude brasileira, ao proferir que

[...] a formulação de uma primeira síntese da história da juventude brasileira permitiunos identificar um traço constante que caracteriza os grupos e movimentos de jovens: a ingenuidade e a honestidade. A exposição das motivações e intenções culturais e políticas apareceu como traço marcante da condição juvenil, que rejeitaria o maquiavelismo como forma de ser dominante.

Nesse sentido, cabe lembrar que rebeldia, inquietação e inconformidade formam parte das culturas juvenis não só nos tempos de outrora, mas também nos jovens contemporâneos os quais se encontram nas salas de aula da modernidade. O fato é que, muitas vezes, quando se recebe esses alunos, não há uma base conceitual clara e sólida, que já deveria ter sido trabalhada desde o Ensino Fundamental.

Sobre essa temática da inconformidade com gerações anteriores ou com o momento atual estabelecido, outro autor muito conhecido e admirado nos estudos de culturas juvenis, Pais (2003, p. 44), aponta que “[...] as culturas juvenis definem-se por relativa oposição à cultura dominante das gerações mais velhas, como uma forma de 'resistência' à cultura da 'classe dominante', quando não mesmo a sua expressão linear'.

\section{A cidade (apropriação do espaço urbano)}

Para que se possa construir o conceito de apropriação do espaço urbano, de maneira a dar sentido de como a pesquisa o entende e o utilizará, faz-se necessária a constituição do entendimento de quatro conceitos importantes que, ao bricolarem-se, compõe o mosaico-entendimento da "apropriação do espaço urbano". São eles: espaço geográfico, espaço urbano, território e lugar.

\section{Conceito de espaço geográfico}

É o objeto de estudo da ciência geográfica, definindo-se, assim, como o conceito máximo desta ciência. No espaço Geográfico estão contempladas as relações intrínsecas entre a natureza e a sociedade e suas consequentes modificações ao longo do tempo. $\mathrm{O}$ conceito de espaço geográfico é definido por Santos (1997, p. 51), quando afirma ser: "um conjunto indissociável, solidário e também contraditório, de sistemas de objetos e sistemas de ações, não considerados isoladamente, mas como o quadro único no qual a história se dá”. Dessa forma, para poder entender com melhor propriedade o espaço urbano, faz-se necessário o entendimento do que é o espaço geográfico, categoria mais abrangente, a qual inclui, então, os próprios espaços urbanos.

\section{Conceito de espaço urbano}

O espaço urbano é definido como "uma unidade de análise consistindo em um conjunto de edifícios, atividades e população conjuntamente reunidos no espaço" (CLARK, 1991, p. 37). Então, estudar o espaço urbano é estudar os fenômenos socio-físico-espaciais das áreas urbanas e suas relações com o mundo em constante construção, reconstrução e desconstrução. Fica clara a expressão do autor quando apresenta uma cidade como um sistema de objetos - edifícios - mas também como um sistema de ações/movimentos atividades e população - assim sendo, podemos entender o espaço urbano pela lógica do próprio espaço geográfico. 


\section{Conceito de território}

A noção do entendimento do conceito de território deriva do entendimento de uma regra básica: território é a expressão de qualquer tipo de poder sobre qualquer tipo de espaço. Podemos entender o território como uma categoria de análise geopolítica, por exemplo, ou simplesmente como um conceito estruturante da geografia nas escolas. Haesbaert (2011) já nos aponta para muitas visões de interpretar a categoria "território". Seriam elas: materialista, naturalista, econômica, jurídico-política, idealista, integradora. O fato é que em todas elas a ideia de poder/apropriação sobre o espaço se faz presente, sentido este ideal para a construção conceitual a que se propusera o presente estudo, na medida em que tratamos da apropriação dos espaços urbanos por jovens contemporâneos.

\section{Conceito de lugar}

O lugar é uma maneira que se tem de interpretar o espaço - conceito maior e objeto de estudo - a partir das relações de identidade e pertencimento estabelecidas com o próprio espaço. Neste sentido, há que se ponderar, para o estudo, que a identificação com determinados espaços urbanos diz muito sobre os pertencimentos dos jovens à e na cidade. É importante aclarar que algum espaço que é lugar para determinado sujeito pode não ser para outro, abrindo-nos a discussão dos espaços topofílicos, como já nos alerta Tuan, 1980 (lugares de pertencimento), e os espaços topofóbicos (de estranhamento). Nesta amplidão de conceitos, o lugar compõe-se, assim, da forma mais próxima que o espaço geográfico pode ser percebido pelos sujeitos.

\section{Amarrando os conceitos}

Neste sentido, ao apresentarmos os dois eixos conceituais básicos da pesquisa: culturas juvenis contemporâneas e apropriação do espaço urbano, pode-se compreender o quão interligados estão tais conceitos, uma vez que o entendimento dos usos-trânsitos juvenis no espaço urbano passam por uma filiação de identidade com espaços da cidade (conceito de lugar) e por sentimentos de posse por espaços urbanos (conceito de território).

A compreensão da ideia de Espaço Geográfico e que este inclui por natureza o espaço urbano, bem como que podemos identificar diferentes territórios que se formam e se desformam a qualquer momento, nos coloca frente ao quão inquietante são estes estudos. Da mesma forma a compreensão do conceito de lugar e as diferentes lugarizações que se estabelecem no espaço urbano pelos jovens contemporâneos, na medida em que citarão, ao longo da pesquisa, espaços de identificação.

\section{Metodologia}

\section{Caracterização básica}

Esta pesquisa caracteriza-se como quantitativo-qualitativa. A primeira etapa, que envolve a aplicação de um questionário virtual caracteriza-se como quantitativa. Estudos quantitativos se caracterizam pela obtenção de resultados a partir de dados numéricos. No caso desta pesquisa, a obtenção de tais dados se realizará através da tabulação e relações feitas a partir das análises das respostas do questionário já referido.

A segunda etapa deste estudo, na qual se prevê a escrita de cartas e o grupo focal, configura-se como estudo qualitativo, uma vez que a atenção principal aos dados de pesquisa não se dará em relação aos números e porcentagens apresentados, e sim aos dados escritos e narrados pelos sujeitos. 
O tipo de pesquisa é classificado como descritiva. Estudos descritivos se caracterizam por descrever o comportamento dos fenômenos, buscando encontrar informações a respeito de uma determinada questão (COLLIS; HUSSEY, 2005).

\section{Cenário da pesquisa}

A pesquisa será realizada, inicialmente, no Colégio de Aplicação da Universidade Federal do Rio Grande do Sul, com os jovens participantes do estudo. Depois de aplicadas as primeiras etapas de coleta de dados o cenário da pesquisa tornar-se-á a própria cidade de Porto Alegre e seus arredores, na medida em que observações necessitarão serem feitas para a análise completa dos achados de pesquisa.

\section{Sujeitos da pesquisa}

O público-alvo da pesquisa ou "sujeitos da pesquisa" é composto por estudantes do Colégio de Aplicação da Universidade Federal do Rio Grande do Sul, com idades entre 15 e 29 anos, o que se enquadra nas concepções de jovens dispostas pelas organizações internacionais, de quem é o sujeito jovem.

\section{Procedimentos para coleta e análise de dados}

Muitas seriam as opções metodológicas a serem adotadas. Nesse contexto, conforme os estudos realizados por Esteban (2010), quando discorre sobre a temática da pesquisa qualitativa em educação, a pesquisa está prevista para ser executada em três etapas fundamentais.

Para que a construção desses caminhos fosse coerente e reflexiva, alguns esclarecimentos cabem ser feitos sobre o que se espera de cada etapa da realização da pesquisa, aprofundando algumas discussões teórico-acadêmicas.

\section{Aplicação de questionário}

No início desta etapa, está prevista a aplicação do questionário, instrumento para a coleta inicial de dados, com distintas questões sobre o tema investigado (VIEIRA, 2009). Estima-se que o questionário seja aplicado em todas as turmas de Ensino Médio do Colégio de Aplicação.

Tabela 1 - Modelo do questionário

1. Sexo:

( ) Masculino ( ) Feminino

2. Idade:

( ) menos de 15 anos ( ) 15 anos ( ) 16 anos

( ) $17 \operatorname{anos}($ ) $18 \operatorname{anos}($ ) mais de 18 anos. Qual?

\section{Onde nasceste?}
( ) Porto Alegre
( ) Grande Porto Alegre
( ) Outras cidades do estado do RS
( ) Outros estados do Brasil
( ) Exterior 
4. Qual a tua etnia?
( ) Branca
( ) Negra
( ) Parda
( ) Indígena
( ) Outra. Qual?

5. Moras em Porto Alegre?

( ) Sim ( ) Não. Onde?

6. Qual o teu bairro?

7. Quais as três primeiras palavras que vêm à tua mente quando pensas em "Porto Alegre"?

8. Assinala o grau de concordância com as frases abaixo:

\begin{tabular}{|c|c|c|c|c|c|}
\hline & 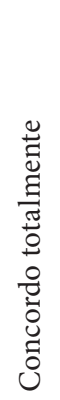 & 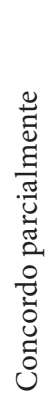 & 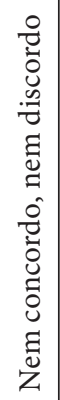 & 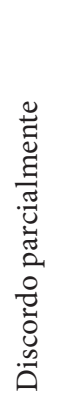 & 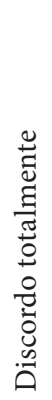 \\
\hline \multicolumn{6}{|c|}{ Porto Alegre é uma cidade boa para se viver. } \\
\hline \multicolumn{6}{|l|}{ Porto Alegre é uma cidade insegura. } \\
\hline \multicolumn{6}{|c|}{ Em Porto Alegre, as pessoas frequentam os espaços públicos. } \\
\hline \multicolumn{6}{|l|}{ Porto Alegre é uma cidade limpa. } \\
\hline Porto Alegre é uma cidade turística & & & & & \\
\hline
\end{tabular}

9. Quais são os 3 espaços que tu mais frequentas em Porto Alegre?

10. Cite dois locais que você ainda não conhece em Porto Alegre, mas gostaria de conhecer.

11. Em tua opinião, quais as principais vantagens de morar em Porto Alegre? 
12. Em tua opinião, quais as principais desvantagens de morar em Porto Alegre?

13. O que tu gostarias de mudar ou construir em Porto Alegre?

14. O que tornaria melhor a vida dos jovens em Porto Alegre?

15. Em relação à alimentação, qual é teu restaurante preferido em Porto Alegre?

16. Qual é teu espaço de lazer preferido em Porto Alegre?

17. Em relação a festas/baladas, qual o teu espaço preferido em Porto Alegre?

18. Como se dá o teu relacionamento com as pessoas?
( ) maior parte na escola
( ) maior parte na internet
( ) maior parte na rua/bairro/condomínio
( ) maior parte na família
( ) outro. Qual?

19. Dos espaços de Porto Alegre indicados abaixo, assinale os que tu frequentaste, ao menos uma vez, no último ano:

\begin{tabular}{|l|l|}
\hline Aeroporto & \\
\hline Cinema & \\
\hline Clube & \\
\hline Estádio de Futebol & \\
\hline Hospital & \\
\hline Igreja & \\
\hline Livraria & \\
\hline Museu & \\
\hline Parque & \\
\hline Praça & \\
\hline Restaurante & \\
\hline Rodoviária & \\
\hline Shopping & \\
\hline Teatro & \\
\hline
\end{tabular}


20. Complete as frases:

\begin{tabular}{|l|l|}
\hline Porto Alegre é... & \\
\hline Porto Alegre não é... & \\
\hline Porto Alegre tem... & \\
\hline Porto Alegre não tem... & \\
\hline
\end{tabular}

Fonte: Elaborada pelo autor.

\section{Análise dos dados e escrita da "carta ao turista"}

Nesta etapa, após a análise dos dados do questionário, prevê-se a realização da escrita da "carta ao turista", movimento metodológico o qual os pesquisadores denominam "metodologia de cartas" e no qual os sujeitos escreverão para um turista hipotético, o qual passará um dia com os mesmos em Porto Alegre (ou em sua cidade). Receberão um papel carta contendo a seguinte inscrição: "Prezado turista: hoje teremos $24 \mathrm{~h}$ na minha cidade, Porto Alegre, e eu gostaria de lhe mostrar alguns dos lugares os quais eu gosto muito de frequentar, por isso...”. Os sujeitos, então, deverão escrever sobre os pontos da cidade os quais levariam o turista para conhecer.

A metodologia de cartas compõe-se de etapa metodológica já descrita por Bastos, Cunha e Mignot (2003); Sierra Blas (2002) e Pereira e Sarti (2010). De todas as formas, em cada estudo citado, os autores utilizaram o recurso metodológico considerando as particularidades de cada situação. Da mesma, forma, a metodologia de cartas da forma a ser empregada neste estudo observará as particularidades e interesses do que se propõe.

\section{Figura 1 - Modelo de papel para a "carta ao turista"}

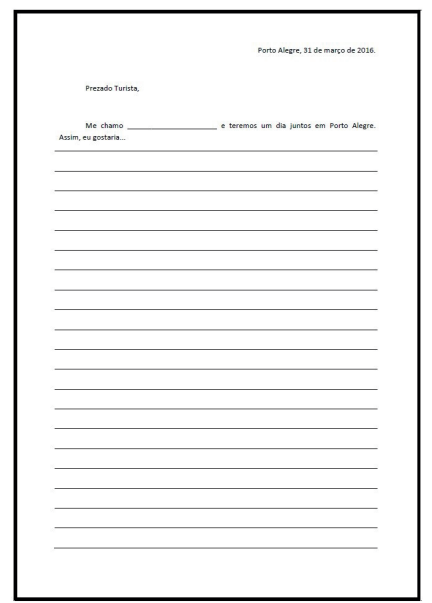

Fonte: Imagem capturada pelo autor.

\section{Observações em campo}

Levantados os lugares citados pelos sujeitos da pesquisa, tanto no questionário, quanto na carta ao turista, partir-se-á para a fase de observações dos três espaços mais citados pelos sujeitos da pesquisa. As observações em campo respeitarão formulário próprio de observação, com o devido registro na caderneta de campo para posterior análise e com os devidos cuidados estratégicos e éticos próprios deste movimento metodológico (ANGROSINO, 2009). 
Quadro 1 - Ficha de observação

Local observado:
Data da Observação:
Horário de início:
Horário de término:

Fonte: Elaborado pelo autor.

\section{Análise dos dados e montagem do grupo focal}

Após a aplicação dos questionários oficiais, da escrita da carta ao turista e das observações em campo, prevê-se uma densa análise dos dados encontrados, que permearão sobre o perfil do jovem contemporâneo e sua relação com a cidade. De posse destes dados, está prevista a condução de grupos focais, com os sujeitos da pesquisa.

\section{Realização de grupo focal}

Antes da escrita do texto final, prevê-se a realização de grupo focal, como "roda de conversa", ou "roda de bate-papo" com os jovens-alunos participantes da pesquisa, no sentido de aprofundar algumas questões encontradas nas etapas anteriores. Neste sentido, de acordo com Barbour (2009), o mediador é o responsável pelos estímulos para que os participantes do grupo focal possam falar sobre determinados assuntos.

O grupo focal será realizado com sete sujeitos participantes das etapas anteriores, por meio de convite. Havendo número maior de interessados do que as vagas haverá sorteio. O grupo focal será realizado em sala específica, com o devido conforto para o silêncio, no Colégio de Aplicação da UFRGS. A rodada de conversa será de, aproximadamente, $1 \mathrm{~h} 30 \mathrm{~min}$, na qual o pesquisador formulará perguntas que emergirem da análise dos dados coletados nas etapas anteriores e, desta forma, estimulará os sujeitos a abordarem tópicos que, porventura, ficaram como pontos de dúvidas.

A sessão do grupo focal será gravada e, posteriormente, transcrita para arquivo de texto, de maneira a facilitar a análise das falas dos sujeitos, que serão categorizadas em categorias estabelecidas a posteriori da realização da atividade.

O grupo focal, com duração de $1 \mathrm{~h} 30 \mathrm{~min}$, será realizado durante dois períodos da disciplina de Geografia, em uma única sessão. Estas aulas serão recuperadas de duas maneiras: (a) através de atividade à distância, fornecida pelo docente aos estudantes e; (b) em horário apropriado para esclarecimento de dúvidas.

\section{Escrita do texto final}

Por fim, de posse de todos os dados encontrados, prevê-se a escrita do texto final, articulando com as leituras realizadas, bem como com a prática docente contemporânea. 


\section{Estrutura básica do texto final}

O Relatório Final para a pesquisa constituir-se-á na seguinte estrutura básica: introdução, objetivos, problema de pesquisa, justificativa, estado do conhecimento, marco teórico, recursos metodológicos, resultados obtidos, análise dos resultados e considerações finais.

\section{Questões éticas na pesquisa}

O projeto de pesquisa apresentou os termos de consentimento livre e esclarecido (aos responsáveis legais dos sujeitos); os termos de assentimento livre e esclarecido (aos sujeitos); e o termo de anuência para realização da investigação (à instituição).

Ao mesmo tempo, o projeto foi aprovado da Comissão de Pesquisa do Colégio de Aplicação da UFRGS e no Comitê de Ética na Pesquisa (CEP/UFRGS), atendendo ao requerido na Resolução 510/2016 do Conselho Nacional de Saúde. 
Cronograma

\begin{tabular}{|c|c|c|c|c|c|c|c|c|c|}
\hline \multicolumn{10}{|c|}{ Quadro 2-Cronograma } \\
\hline & & $\begin{array}{l}\text { Leituras e } \\
\text { realização } \\
\text { de grupo } \\
\text { de estudos }\end{array}$ & $\begin{array}{l}\text { Aplicação } \\
\text { de ques- } \\
\text { tionário }\end{array}$ & $\begin{array}{l}\text { Análise } \\
\text { dos dados } \\
\text { e escrita } \\
\text { da "carta } \\
\text { ao turista" }\end{array}$ & $\begin{array}{l}\text { Observa- } \\
\text { ções em } \\
\text { campo }\end{array}$ & $\begin{array}{l}\text { Análise } \\
\text { dos } \\
\text { dados e } \\
\text { montagem } \\
\text { do grupo } \\
\text { focal }\end{array}$ & $\begin{array}{l}\text { Reali- } \\
\text { zação de } \\
\text { grupo } \\
\text { focal }\end{array}$ & $\begin{array}{l}\text { Inter- } \\
\text { venções } \\
\text { urbanas } \\
\text { pelos } \\
\text { jovens do } \\
\text { Colégio de } \\
\text { Aplicação } \\
\text { da UFRGS }\end{array}$ & $\begin{array}{l}\text { Escrita } \\
\text { do texto } \\
\text { final }\end{array}$ \\
\hline \multirow{10}{*}{$\begin{array}{l}2 \\
0 \\
1 \\
8\end{array}$} & Mar. & $\mathrm{X}$ & & & & & & & \\
\hline & Abr. & $\mathrm{X}$ & & & & & & & \\
\hline & Maio & $\mathrm{X}$ & & & & & & & \\
\hline & Jun. & $\mathrm{X}$ & & & & & & & \\
\hline & Jul. & $\mathrm{X}$ & & & & & & & \\
\hline & Ago. & & $\mathrm{X}$ & & & & & & \\
\hline & Set. & & $\mathrm{X}$ & & & & & & \\
\hline & Out. & & & $\mathrm{X}$ & & & & & \\
\hline & Nov. & & & $\mathrm{X}$ & & & & & \\
\hline & Dez. & & & $\mathrm{X}$ & & & & & \\
\hline \multirow{12}{*}{$\begin{array}{l}2 \\
0 \\
1 \\
9\end{array}$} & Jan. & & & $\mathrm{X}$ & & & & & \\
\hline & Fev. & & & $\mathrm{X}$ & & & & & \\
\hline & Mar. & & & & $\mathrm{X}$ & & & & \\
\hline & Abr. & & & & $\mathrm{X}$ & & & & \\
\hline & Maio & & & & $\mathrm{X}$ & & & & \\
\hline & Jun. & & & & $\mathrm{X}$ & & & & \\
\hline & Jul. & & & & $\mathrm{X}$ & & & & \\
\hline & Ago. & & & & & $\mathrm{X}$ & & & \\
\hline & Set. & & & & & $\mathrm{X}$ & & & \\
\hline & Out. & & & & & & $\mathrm{X}$ & & \\
\hline & Nov. & & & & & & $X$ & & \\
\hline & Dez. & & & & & & $\mathrm{X}$ & & \\
\hline \multirow{8}{*}{$\begin{array}{l}2 \\
0 \\
2 \\
0\end{array}$} & Jan. & & & & & & & $\mathrm{X}$ & \\
\hline & Fev. & & & & & & & $\mathrm{X}$ & \\
\hline & Mar. & & & & & & & & $\mathrm{X}$ \\
\hline & Abr. & & & & & & & & $\mathrm{X}$ \\
\hline & Maio & & & & & & & & $\mathrm{X}$ \\
\hline & Jun. & & & & & & & & $X$ \\
\hline & Jul. & & & & & & & & $\mathrm{X}$ \\
\hline & Ago. & & & & & & & & $\mathrm{X}$ \\
\hline
\end{tabular}




\section{Orçamento}

Não há previsão de gastos no referido projeto de pesquisa.

\section{Riscos e benefícios do projeto}

\section{Riscos ou desconfortos em relação à participação na pesquisa}

O desconforto que o sujeito poderá sentir é o de compartilhar informações pessoais ou confidenciais, ou em alguns tópicos que ele possa se sentir incômodo em falar. O pesquisador deixará claro que o sujeito não precisa responder a qualquer pergunta ou parte de informações obtidas, se sentir que ela é muito pessoal ou sentir desconforto em falar.

Benefícios provenientes da realização do projeto de pesquisa

Para além da geração de conhecimento sobre o campo de pesquisa das juventudes e os benefícios direcionados à sociedade e aos futuros jovens, os sujeitos da pesquisa não recebem nenhum benefício direto.

\section{Produções e impactos esperados}

Quadro com resumo das principais publicações esperadas

Quadro 3 - Resumo das principais publicações esperadas

\begin{tabular}{|l|c|}
\hline \multicolumn{1}{|c|}{ Índice } & Quantidade esperada \\
\hline Artigos científicos & 4 \\
\hline Trabalhos completos em eventos & 3 \\
\hline Capítulos de livros & 3 \\
\hline
\end{tabular}

Fonte: Elaborado pelo autor.

\section{Detalhamentos dos avanços e impactos potenciais esperados, incluindo o efeito multiplicador do projeto}

Impactos institucionais: universidade/unidade/departamento

Os resultados institucionais esperados desta proposta são:

»O conhecimento de quem é o jovem estudante do Colégio de Aplicação da UFRGS, possibilitando um melhor preparo para as atividades ali desempenhadas;

"A projeção do Colégio de Aplicação da UFRGS enquanto instituição que reconhece seus estudantes e que lhes dá voz, sabendo que tal atitude impacta positivamente nas relações estabelecidas no ambiente escolar. 
Impactos sociais (extensão)

Os impactos sociais esperados desta proposta são:

»A possibilidade de realização do Projeto de Extensão no qual os jovens-alunos realizem intervenções urbanas em sua cidade, exercitando a crítica social e possibilitando reais melhorias para a cidade;

»O envolvimento com as comunidades de origem dos jovens participantes do estudo, na medida em que são estimulados a estender suas ações cidadãs.

Impactos acadêmicos (ensino)

Os impactos no ensino esperados desta proposta são:

» A introdução da cultura de conhecer o estudante em seus aspectos sociais, culturais e psicológicos;

» A criação de uma agenda de professores-pesquisadores sobre a temática do urbano, estendendo assim o trabalho com esta proposta para além da sala de aula.

Impactos técnico-científicos (pesquisa)

Os impactos na pesquisa/grupos de pesquisa esperados desta proposta são:

"A consolidação de uma parceria entre o Grupo de Estudos e Pesquisas sobre as Juventudes Brasileiras e o Colégio de Aplicação da UFRGS;

»A criação de um Grupo de Trabalho (GT) do Colégio de Aplicação da UFRGS, destinado à realização de pesquisas que envolvam, nos diferentes aspectos, o público estudantil da instituição.

\section{Referências}

ANGROSINO, Michael. Etnografia e Observação Participante. Porto Alegre: Artmed, 2009.

BARBOUR, Rosaline. Grupos Focais. Porto Alegre: Artmed, 2009.

BASTOS, Maria H. C.; CUNHA, Maria T. S.; MIGNOT, Ana Chrystina V. (org.). Destinos das letras: história, educação e escrita epistolar. Passo Fundo: Ed. UPF, 2003.

CACCIA-BAVA, Augusto; COSTA, Dora Isabel Paiva da. O lugar dos jovens na história brasileira. In: CACCIA-BAVA, Augusto; FEIXA PÀMPOLS, Carles; CANGAS, Yanko (org.). Jovens na América Latina. São Paulo: Escrituras Editora, 2004. p. 22-47.

CALADO, Flaviana Moreira. O ensino de Geografia e o uso dos recursos didáticos e tecnológicos. Geosaberes, Fortaleza, v. 3, n. 5, p. 12-20, 2012.

CAVALCANTI, Lana de Souza. A geografia escolar e a cidade: ensaios sobre o ensino de geografia para a vida urbana cotidiana. Campinas: Papirus Editora, 2008.

CLARK, David. Introdução à Geografia Urbana. Rio de Janeiro: Bertrand Brasil, 1991.

COLLIS, Jill; HUSSEY, Roger. Pesquisa em Administração: um guia prático para alunos da graduação e pós-graduação. Porto Alegre: Bookman, 2005.

ESTEBAN, María Paz Sandín. Pesquisa qualitativa em educação: fundamentos e tradições. Porto Alegre: Artmed, 2010.

FUNDAÇÃO DE ECONOMIA E ESTATÍSTICA (FEE). Estimativas Populacionais - 2016. FEE: Porto Alegre, 2016. Disponível em: https://www.fee.rs.gov.br/indicadores/populacao/estimativas -populacionais/. Acesso em: 15 maio 2018.

FEIXA PẢMPOLS, Carles. A construção histórica da juventude. In: CACCIA-BAVA, Augusto; FEIXA PÀMPOLS, Carles; CANGAS, Yanko (org.). Jovens na América Latina. São Paulo: Escrituras Editora, 2004. p. 65-89. 
FEIXA PÀMPOLS, Carles. La ciudad invisible: territórios de las culturas juveniles. In: CUBIDES C., Humberto J.; TOSCANO, Maria Cristina Laverde; VALDERRAMA H., Carlos. Viviendo a toda: jóvenes, territorios culturales y nuevas sensibilidades. Santa Fe de Bogotá: Ediciones Universidad Central: Siglo del Hombre Editores, 1998. p. 17-39.

HAESBAERT, Rogério. O mito da desterritorialização: do fim dos territórios à multiterritorialidade. Rio de Janeiro: Bertrand Brasil, 2011.

INSTITUTO BRASILEIRO DE GEOGRAFIA E ESTATÍSTICA (IBGE). Censo Demográfico 2010. Rio de Janeiro: IBGE, 2010. Disponível em: www.ibge.gov.br. Acesso em: 15 maio 2018.

KATO, Danilo Seithi; KAWASAKI, Clarice Sumi. As concepções de contextualização do ensino em documentos curriculares oficiais e de professores de ciências. Ciência \& Educação, Bauru, v. 17, n. 1, p. 35-50, 2011.

PAIS, José Machado. Culturas Juvenis. Lisboa: Imprensa Nacional-Casa da Moeda, 2003.

PAIS, José Machado. Ganchos, Tachos e Biscates: Jovens, Trabalho e Futuro. Porto: Ambar, 2001.

PEREIRA, Mateus Henrique de Faria; SARTI, Flavia Medeiros. A Leitura entre Táticas e Estratégias? Consumo Cultural e Práticas Epistolares. Revista História da Educação, Pelotas, v. 14, n. 31, p. 195-217, maio/ago. 2010.

SANTOS, Milton. A Natureza do Espaço: Técnica e Tempo. Razão e Emoção. São Paulo: Hucitec, 1997.

SIERRA BLAS, Verónica. Escribir y servir: las cartas de una criada durante el franquismo. Signo: Revista de Historia de la Cultura Escrita, Alcalá de Henares, n. 10, p. 121-140, 2002.

TUAN, Y-Fu. Topofilia: um estudo da percepção, atitudes e valores do meio ambiente. São Paulo: Difel, 1980.

VIEIRA, Sônia. Como elaborar questionários. São Paulo: Atlas, 2009.

WARTHA, Edson José; SILVA, Erivanildo Lopes da; BEJARANO, Nelson Rui Ribas. Cotidiano e contextualização no ensino de química. Química Nova na Escola, São Paulo, v. 35, n. 2, p. 84-91, maio 2013. 
